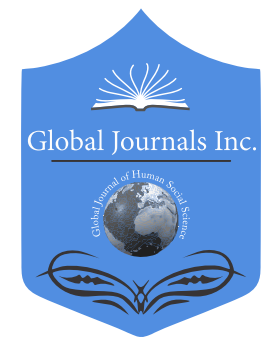

\title{
The Participation of Players in the Composition of the Locative Structure in Niantic Games
}

By Bruno Assad Admus Paixão \& Joao Victor Boechat Gomide

Universidade Fumec

Abstract- This study presents and discusses how the participation of players happens in the structure and validation of the geographical area of interest in Niantic locative games. To better understand this process, how the cities are represented and simulated inside the structure of the locative games is enlighten. This structure and the Ingress Mechanics evoke in the players two types of motivation, intrinsic and extrinsic, and it makes them participate in the validation process of areas of interest for the games around the world, which are used in Pokémon Go as well. The result of this process corresponds to the way Niantic maps physical spatiality for its locative games.

GJHSS-H Classification: FOR Code: 950407, 110699

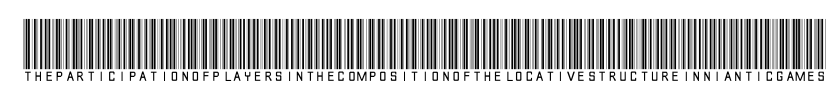

Strictly as per the compliance and regulations of:

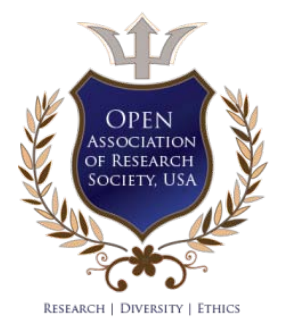

(C) 2019. Bruno Assad Admus Paixão \& Joao Victor Boechat Gomide. This is a research/review paper, distributed under the terms of the Creative Commons Attribution-Noncommercial 3.0 Unported License http://creativecom-mons.org/licenses/by-nc/3.0/), permitting all non-commercial use, distribution, and reproduction in any medium, provided the original work is properly cited. 


\title{
The Participation of Players in the Composition of the Locative Structure in Niantic Games
}

\author{
Bruno Assad Admus Paixão ${ }^{\alpha} \&$ Joao Victor Boechat Gomide ${ }^{\sigma}$
}

\begin{abstract}
This study presents and discusses how the participation of players happens in the structure and validation of the geographical area of interest in Niantic locative games. To better understand this process, how the cities are represented and simulated inside the structure of the locative games is enlighten. This structure and the Ingress Mechanics evoke in the players two types of motivation, intrinsic and extrinsic, and it makes them participate in the validation process of areas of interest for the games around the world, which are used in Pokémon Go as well. The result of this process corresponds to the way Niantic maps physical spatiality for its locative games.
\end{abstract}

\section{InTRODUCTION}

T he appropriation of areas of the city to create the locative games' world is a defining feature for its success. These areas must be some way validated through some process, and this is a challenge for games that players may play in different parts of the world.

This study analyses how Niantic, which produced Ingress and Pokémon Go, was able to develop a strategy to appropriate of several regions of cities around the globe for the Mechanics, narratives, and spatiality of its locative games using the involvement of its players. For this study, besides intensely playing the games, the authors interviewed players of several levels and performed a bibliographic review of the available literature.

On the next section "Evolution of Niantic locative games" a brief historical context of the company's locative games is presented involving Field Trip, Ingress and Pokémon Go, with the construction of the database of common interest areas to the games. The section "Methodology" encompasses the bibliographic review, and exploratory research carried out in this study, aiming at comprehending how the validation of areas of interest to the games through the involvement of players, who act for free to the company happens.

In the following section "The spatiality and involvement of players" the concepts found in the bibliographic review are articulated to comprehend how the players use the elements of cities and the virtual setting are. In "Current locative structure", the city is analyzed through its immediacy and heterotrophic and isotropic representation. In "Players interaction with Ingress" the players are divided inside the Bartle profiles,

Author: Universidade Fumec. e-mail: brunoassadmg@yahoo.com.br which are used as guides to be able to relate research data on the involvement of players. In this section are also presented the research result, comparing Ingress and Pokémon Go interfaces and statements of its respective players. The comparison made possible to identify how the involvement and motivation of players collaborate with the spatiality of these locative games.

\section{il. EVOlution of Niantic locative GAMES}

Niantic Inc. was a Google startup created in 2010 under the name Niantic Labs, and it became independent in 2015. Niantic developed Field trip application and the games Ingress and Pokémon Go, sequentially, all of them involving the urban furniture and cultural objects of real cities. Each new launching was possible through the improvement of the cities and its cultural objects database - developed by the company, in partnership with Google- comparing to the previous application, and the embraced technologies as well (Niantic 2018).

The first application developed by Niantic, Field Trip, launched in 2012, used a data repository of the company with information and images of a reduced number of geo-referenced monuments. Initially, it worked only in the United States but nowadays it works in many cities around the world, which have maps on Google Maps and information on areas of interest that are geo-located. Field Trip is like a tourist guide providing messages in text, images, and voice for smartphone or tablet of areas of interest regarding architecture, lifestyle, historical or cultural importance, as well as restaurants, bars, theaters, movie theaters, museums, galleries or outdoor art. These areas appear on the device screen with images next to the name that identifies the place. By opening the files, detailed information about these places is presented, based on publication from websites that are specialized and are also partners of Niantic. Specific icons mark the areas of interest that may be visualized on Google Maps, inside the application interface and clicking on it the same information about the place appears. The application detects when the user is moving, and it automatically provides information on locations and experiences of interest in the neighborhood. In one of its operation mode Field Trip sends text or voice notifications to the 
user's device when s/he approaches one of her/his areas of interest.

The locative game Ingress was launched in November of 2012, at first only for invited users and using the Android operating system. Different from Field Trip, it has a narrative and mechanics. As a part of the game, the users are invited to take photographs of monuments and important places in their cities and send it to the developer company, and they may become a part of the game as portals. These references are added to the Niantic database to generate new information about areas of interest around the world. The player navigates in his neighborhood catching areas of interest that are portals and developing tasks related to his geographical location.

The game script happens on the basis of the idea of a new type of matter called Exotic Matter (XM) that was discovered along with the Higgs boson at CERN. The XM is being used to enslave the human race or to evolve a higher level of awareness, depending on the player's choice. By entering the game for the first time, using his Google email to access, the player must choose one of the groups that compete in the game: Resistance that seeks to destroy the exotic matter to make mankind free of the XM control; Enlighten that pursues to control the XM power in order to expand mankind's awareness. Once the players choose a side there is no way of changing it, unless a new Google account is started (Ingress 2018).

The game's navigation uses a map of the player's neighborhood in its interface with the location of portals nearby, which were mapped beforehand. Portals are areas of interest in the real city, such as a theater, a movie theater, a monument, a statue, graffiti, museums, and buildings, which are not limited to conventional history. These portals started to be mapped before the game was first released to the great public by players who received an invitation to install it in their smartphones and play it and by information of Google as well. The mapping of portals continues nowadays with suggestions sent by the players. All portals have geo-referenced images and information sent by players.

The map extracted from Google Maps is stylized with a change in the colors and information to create one of the interface options of the game in a different representation of the city. In the map's visualization, the player is identified by an arrow with a circle around it, and it considers the accuracy of the GPS. By approaching physically of the portal and clicking on its location in the map of the game's interface, information and images of the portal appear on the mobile device screen with the possibility of either catching areas and guns or it entirely.

Many of the acquisition missions are performed in a group, covering referenced areas of the city because of its cultural, historical or political importance of that community as stated by Hatfield (2018) when he followed a Resistance group in London. He mentions cases of groups that rented an airplane to go to a remote location in Alaska and catch portals in to expand their control zone. The game promotes events called Anomalies when the groups reunite to fulfill missions that involve great distances and dislocation around the globe.

In some situation, the game allows players to indicate areas of the city to become portals. However, there are criteria for acceptance, such as historical, educational, architectural, artistic value or traditional spaces. Besides these criteria, Ingress requests the submission of a recent photograph in high quality to collaborate in the acceptance process. The Help tool of the game (Ingress 2018) states that it does not accept as portals places with no safe access to pedestrians, living beings, natural landscapes, seasonal buildings, pictures of others, private residential property, fireman quarters, police station, hospitals, and high/elementary school. The quality check of the portals is not exclusive of Ingress; the players may report portals through the game's interface stating it does not exist or it is a nonsafe place, it is not accessible for people, a copy of another portal or to describe other reason. Moreover about this interaction Ingress enables the players to add photographs and additional information to the implemented portals that will be evaluated. At the end of 2018, the Ingress interface changed and the game started to call Ingress Prime. The modification was only in the visual interface. The sounds, areas of interest and score are still the same.

Pokémon Go was developed in a partnership with Google and Nintendo, using the database and the experience acquired with Ingress, and it was launched in some countries at first. The player catches characters throughout the city and heads to the Poke Stops to obtain items respectively and participate in fights. The Pokémons appear in the device screen as if they were in the real setting through a camera and the device's gyro sensor. It is an improvement compared to Ingress, which used maps and photographs of portals to be captured instead of the camera image in real time. The Poke Stops and the Pokémon Gyms are at the same portals of Ingress.

In these two games, Ingress and Pokémon Go, the players must move around the city to score and catch tools of the game, walking through the cultural objects of the city. With these areas mapped and available in a database, in thousands of cities worldwide, new applications are possible. The next launching by Niantic might be a locative game based on the Harry Potter series.

\section{Methodology}

To describe the locative structure of Niantic games and to understand how the players' participation 
happens for the spatiality expansion, bibliographic research was carried out and interviews with players from several levels of skills, from both Ingress, and Pokémon Go.

Aiming at seeking researches that related to these themes, the DECIDE framework structure was used (PREECE et al., 2013). The consulted database was Ebsco Host, CAPES Portal, Cite Seerx and SSRN that is a digital library with a collection of over 700 thousand articles. The strings of words used were: Locative Experiences, Locative games, location-based games (LBGs), locative case, game culture, game studies, ingress, augmented reality, site-specific, urban games, hybrid games, spatiality.

The searched terms were divided into three groups: cities and electronic games (locative games, location-based games, lbgs, hybrid games, and urban games), cities (site-specific), and technology and culture (locative case, game culture, game studies, ingress, augmented reality, locative experiences and, spatiality).

Although 60 types of researches were obtained, only 27 were in line with this study objectives, due to the fact they discuss concepts of space, representation, and simulation from the player's involvement point of view. The other 33 researches were not used because of the thematic aimed at the computational codes implementation and the teaching-learning process.

Regarding the exploratory research with Ingress and Pokémon Go players, two participant observations were performed as well as distance interview and surveys. The first participant observation was carried out with a Pokémon Go player. In this participant observation, the researcher was with Ingress on his cell phone while the player had Pokémon Go. This technic was applied to identify the existence of a strategic relationship between these two Niantic locative games. Subsequently another participant observation was performed at an event of Ingress with other 30 players.

An interview with one of the Ingress players and 15 interviews with a group of Ingress players on the Telegram application were performed after. Some players were interviewed through instant messaging apps and surveys applied to check this strategical approach. An online survey about the relation of Niantic games and spatiality was applied and got 28 answers. Besides, the comments about the games on Google Play were consulted, and three of them that related to this study aim were selected.

The results of the bibliographic research and the interaction with the players are presented in the next section.

\section{Spatiality and Involvement of Players}

Regarding the concepts that involve the cities and the locative games, it is necessary to define the difference between representation and simulation. Representation corresponds to a chain of meanings that provide material for esthetical, narrative, mechanical and technological attributes of locative games.

Walther (2005) presents two auxiliary concepts, which are the heterotrophic space and isotopic space. For the author, the heterotrophic space encompasses all daily complexities. The heterotrophic space, in both Ingress and Pokémon Go corresponds to the public spaces in the cities, the traffic, and weather for instance.

According to Walther (2005), the isotropic space is composed by coordinates dispersed by the ambiance. Applying this concept to this study's objective, it would be like a system that stores the position of every element of the game, considering movable positions - the player and the characters to be captured on Pokémon Go - and strategical positions PokeStops and Pokémon Gyms on Pokémon Go and Portals on Ingress.

These characteristics according to Murray (2003) may be applied the digital settings because virtuality enables the representation of navigable spaces. Considering that, it is possible to identify physical geographical representations and their associations in virtual ambiances.

Physical representations and their corresponding areas in virtuality are systemized in a platform to create an experience for the players. In this systematization, the simulative character of the games is inserted because the elements are presented to the players in to establish a dynamic activity regarding interaction. According to Dovey and Kennedy (2006), representation is the way to access simulation of the world controlled by rules, that means representation is a component of simulation. Also Kiefer and Scheider (2017) state that simulation is a trigger of events defined by the computer to impose a change in the player status.

Simulation extrapolates the amusement field when it is used on military training (Dovey and Kennedy; Hill and Hodson 2014). The US Department of Defense works with three modalities of simulation - live, virtual and created -, which consist of the status variation of physical reality and simulation between humans and systems (Hill and Hodson 2014).On "live" the operation of the systems and the targets are real, that means inside a simulative ambiance in the real world a pilot trains with real equipment in a real target. On "virtual simulation" a virtual ambiance is created to simulate an attack activity, in which the human pilot has to reach the proposed goal correctly. Finally, on "Created simulation" all aspects involved, such as the pilot, the target, the environmental conditions are simulated.

Another way of thinking about simulation in locative games consists of the adaptation of the digital ambiances characteristics of Murray (2003) because the narrative may be classified as a type of representation. 
From now on, the digital ambiance has four characteristics that are procedural, participative, spatial and encyclopedic (Murray 2003).

For Murray (2003), the procedural characteristic corresponds to the interpretation provided by the electronic device to identify patterns of complex behavior. This characteristic is related to the electronic device activity to classify the representative insertions of users, to create a simulation consistent to interaction through its pre-established rules. From the same point of view, Dovey and Kennedy (2006) state that simulation is based on a dynamic electronic system that models the complex ambiance with many interconnected coincidences.

About the participative characteristic, for Murray (2003) it is an expansion of the procedural character because they not only provide automatic behaviors to responses but actively interfere in the context and remake behaviors. The feedback system is the answer to the player's decision making, influencing the score, levels, scoreboard or the progress bars (McGonigal 2012). On Ingress, the feedback is not only visual but audible. The game informs by an audible signal to the player not only the approximation of a portal but the possibility to perform connections between portals of the same group, the possibility of either collecting items or to attack the player's enemy portals according to the participative proposal presented.

Regarding the spatial characteristic, Murray (2003) states that its principal aspect is not related to chart, tridimensional images exhibition but to the interactive process of the navigation. Schell (2008) complements this idea by stating the game happens in some place. To the locative games, spatiality simulation is simultaneously divided into virtual, real and mixed. While in Ingress it is possible to identify an attack on a portal as well as to move around the city to perform a strategy.

Voluntary participation corresponds to the level of the players' aware acceptance of the goals, the rules and the feedback to begin or leave the game (McGonigal 2012). This characteristic is noticed on Ingress because time is not accounted for and while a diversity of portals through the city exist, the player may continue his game.

The locative game spatiality composition is not restricted to the relation between the physical elements of the city and virtual components but a fictional relationship between both. This spatiality is only accessed by representations and languages that are classified in three spatial instances (Fragoso 2015):

- Imaginary space: corresponds to the immaterial ambiance that supports fictional events.

- Enunciation space: corresponds exclusively to the representations that form the aesthetical composition of the image. This spatial instance does not approach the aesthetic related to the electronic device, for instance, the screen.

- Material space: is the real world composed of all the possible elements, such as the players, the electronic devices and the close objects.

It may be deduced by applying spatial instances to Ingress that the imaginary space and the enunciation space lean on the material space. The material space composes the city spatiality formed by streets, buildings, historical monuments, people and weather. The imaginary space of Ingress is a translation of the cities material space of an immaterial and fictional character. In brief, on Ingress, a competition between Resistance in blue and Enlightened in green was established to control areas of the city. The control of the areas of the city consists of occupying an empty portal or destroying portals that are under the domain of the enemy and dominate them. That way, the geography of the imaginary space is not set, and it changes after each successful action of the players.

In the enunciation space, the elements of the material space are adapted to the locative games. The areas of the city of material space are configured as portals in the Ingress interface that means in the enunciation space. In Pokémon Go these areas of the city become gyms or Poke Stops in the enunciation space.

The player's experience may be described by the adaptation of agon concepts and mimicry to the locative games. Agon corresponds to the competitive characteristic of the game (Callois 2001). On Ingress, the agon characteristic consists of the dispute between the groups Enlightened and Resistance for the portal spread around the city. This aspect is not on Ingress so in a few cases, some players suspected of the question of this research, judging that the interviewer was a spy. A player even said that if the interviewer were from the enemy team the interview would end at the moment, and he even justified himself saying that he is very competitive.

The mimicry corresponds to the temporary acceptance of the imaginary universe of the game (Callois 2001).On Ingress, the mimicry is present in the game's narrative. The Enlightened believe in the study of the Exotic Matter (XM) while the Resistance considers it a threat to freedom. Mimicry is still present in Ingress because of the way the game performs its interaction with the world. A monument, a house or a simple wall are just portals of Exotic Matter (XM), and they may have two types of status: dominated or free. When they are dominated, they have the color that corresponds to the group that holds the domain of it, green or blue. The free portals remain gray until one group member of one of the factions dominates it. Regarding mimicry, a player pointed out as his great motivation to play Ingress the fact of acting discreetly on the streets as if he were a 
secret agent to save "the world from the Enlightened". From now on, it is easy to realize how the game extrapolates the human life sphere because it creates an autonomous reality generating its phenomena (Huizinga 1968).

According to Attfield et al. (2011), the involvement is the combination of emotional, cognitive and behavior existing between the players and some resource of the game for some time. To study the involvement of players in Ingress, it was necessary to detail the locative game structure with the data obtained in the research. To collaborate with the structure detailing, an elementary tetrad of the game (Schell 2008) and the Bartle profiles were used as explained below.

According to Schell (2008), all the games are composed for four components that form an elementary tetrad. These four elements are the aesthetic, mechanics, the story and technology used in each game. To the locative games, the aesthetic refers to the sensorial quality of the interface that mediates the game and the city. The mechanics consists of the main options of the interaction of the players to reach satisfactory and compensatory rewards. The story corres ponds to the narrative proposed by the game. At last, technology implements all previous concepts, such as interactivity, simulation, feedback and possible configurations of the game.

The Bartle profiles (1996) present a proposal of classification of the Role Playing Game (RPG) online games persona that was never adapted to the locative games. In this case, the spatiality of the RPG online games consists of the city in electronic devices and the integration between them. The players have fun as four personas, which are achievers, explorers, socializers, and killers varying their interaction between two sources of interest that are the world and other players.

After that, the aspects of each profile that will be explored again from the Ingress's point of view on one of the upcoming section are summarized. The achievers are players that determine goals to accumulate items, while the explorers are players that pioneer most of the game ambiances. The explorer profile is very present in locative games because going out through the exterior ambiance, not staying in a closed ambiance and having possibilities to explore the real world is relevant to the players. These statements were noticed on the answers of the players to the virtual survey. Both the achievers and the explorers prioritize the interaction with the game's space.

To the socializers, the priority is communication. The socializers are a profile apparent on Ingress players because, besides the communities to discuss strategies and to clarify doubts the players have, Niantic performs events between the players in several cities worldwide to promote the game. At last, the killers are players that aim at the destruction of other players. Both socializers and killers prioritize the interaction with other players (Bartle 1996).

To be able to understand how the reward system of Ingress players works the elementary tetrad of the game (Schell 2008) was combined with the (Bartle 1996) profiles. Figure 1 exemplifies how this relationship works.

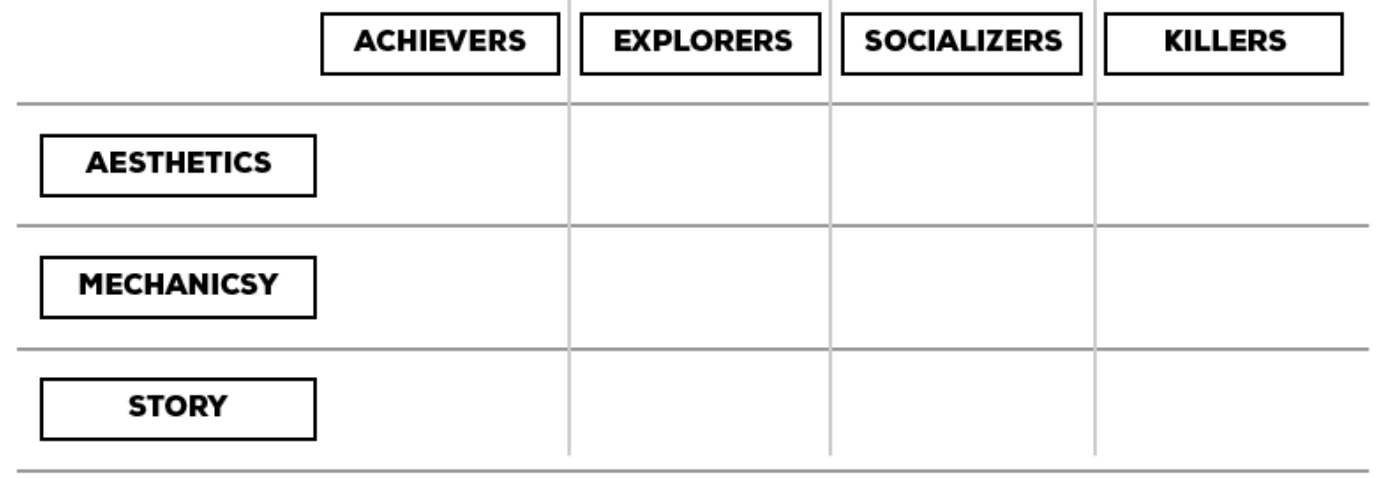

TECHNOLOG Implements interactivity, user control and simulation and geolocation

Figure 1: The relationship between the elementary tetrad of the game and the Bartle profiles

Technology is a constant aspect in all of the profiles because it does not depend directly on the player but the electronic device and the Internet connection networks.

From the player's point of view, it is the social interaction and the geographical exploration, in a true immersion that enables to flow in this mix between real and virtual world, where the physical references lead to an equivalent portal in the virtual world. That, many times leads to a sense of time and identity loss in a deep process of immersion. The flow is a state, in which they are so involved in an activity that nothing else 
seems to matter; the experience is so pleasant that people will do it even at a great cost, by the simple interest in doing it (Csikszentmihalyi 2009).

Motivation may be classified as extrinsic and intrinsic. Extrinsic motivation corresponds to work that was performed aiming at the actual reward, such as money or score, while intrinsic motivation consists in the performance of activity only by the personal interest, regardless the effort or reward (Matlin 2009).

By applying these concepts, it was possible to identify a relation between the motivation of players and the spatiality of Ingress and Pokémon Go that may be noticed in a commentary about Ingress at Google Play from a Pokémon Go player; it is on Figure 2.

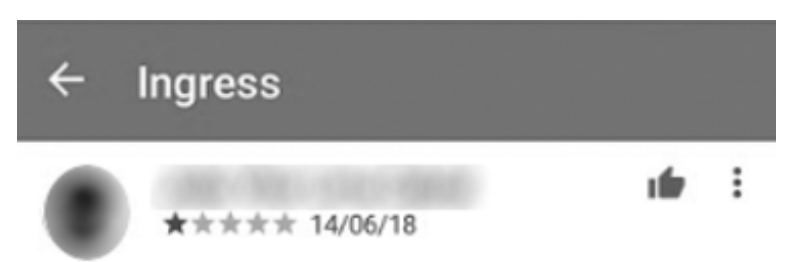

Horrivel, tentam forçar os jogadores de pokemon go a jogar esse jogo só pra fazer pokestops

Figure 2: Figure from Google Play

By analyzing this commentary with the data obtained on the survey with Ingress players, it was specified that Niantic uses Ingress to create the spatiality of Pokémon Go. In the case of the player who commented (Figure 2), it is obvious that his motivation is extrinsic because his goal is the expansion of Pokémon Go spatiality. There are channels of advice on YouTube that teach strategies to speed up the process of Ingress portal migration to Pokémon Go, for instance, to fulfill information that are empty in the figure description.

However, the research was able to identify users that changed their motivation related to Ingress. That was also acknowledged in the commentary at Google Play store on the game, as showed in Figure 3.

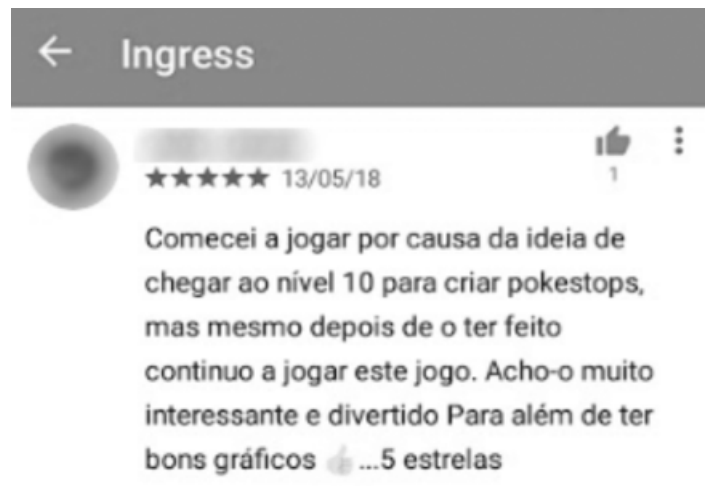

Figure 3: Figure from Google Play
The translation of thetext:"I started to play with the idea of reaching level 10 to create Poke Stops, but even after I did it I stillplay it. I find it very interesting and fun. Besides, it has good graphics... five stars."

\section{Locative Structure}

To understand how the current locative structure is implemented, it is necessary to analyze the city by its composition and forms of mediation. Through the composition perspective, the city is formed by heterotrophic and isotopic information. Heterotrophic information consists of the most subjective facet of the urban ambiance composed by image scenery and social aspects. Isotropic representation has a more technical characteristic encompassing geographical coordinates and technological infrastructure of services and devices. (Fragoso 2015; Walther 2005; Cresswell 2009).

As forms of mediation, the city is analyzed through the immediacy and hypermediacy perspective. According to Bolter and Grusin (2000), immediacy is when the ambiance and technology (services and devices) establish a high level of symbiosis that it is not possible to identify on an interface. Diametrically, according to the authors the hypermediacy is, that means the interface is evidenced on purpose. Applying these concepts to the locative structure of Ingress, when the player performs an activity in the game, such as attacking a portal, the city is hyper mediated because it is necessary the use of cell phone as an interface. However, moving to another area of the city is a characteristic of immediacy because the urban scenery is integrated into the game.

On this immediacy proposal of Bolter and Grusin (2000), to access the space created by the game, in the imaginary space, it is essential the use of an interface. The fact of the physical ambiance of the city is annexed to the game as an important motivation to the player, as was found in the result of the surveys. The interface is limited to the cell phone when the user moves around the city. Inside the line of this study, immediacy and hypermediacy correspond to the player's uses. Hence, the Board 1 is the result of the analysis of concepts of Heterotrophic Representation and Isotropic Representation (Walther 2005), the principles of Immediacy and Hypermediacy (Bolter and Grustin 2000) and the data collected with the players of Ingress and Pokémon Go to be able to deepen the locative structure in these games.

Board 1: Mediation of the city: the adaptation of Immediacy and Hypermediacy (Bolter and Grusin 2000) and Heterotrophic Representation and Isotropic Representation (Walther 2005) 


\begin{tabular}{|c|l|}
\hline \multicolumn{2}{|c|}{ Mediation of city in Ingress } \\
(Heterotrophic Representation and Isotropic Representation) \\
\hline \multicolumn{1}{|c|}{ Uses of Immediacy } & \multicolumn{1}{c|}{ Uses of Hypermediacy } \\
\hline Movement around the city & $\begin{array}{l}\text { Performance of the game's mechanicsy through the } \\
\text { cell phone. }\end{array}$ \\
\hline
\end{tabular}

Source: Research data

The city and the Ingress integrate their spatiality to promote the game's dynamics. According to Walz (2010), this phenomenon is the hybrid space, in which materiality and immateriality determine an indivisible fusion to the locative game, both the physical attributes of the city and the immateriality of the mechanics and stories of the game are encapsulated in a single spatial dimension of Ingress. The hybrid space exposes the rules that limit the player's activities, the possible changes of status of the game for progress and feedbacks.

\section{Board 2: Current locative structure configuration}

The city and its heterotrophic and isotropic representation.

\section{Electronic hypermediacy} the hybrid space.

Technological infrastructure: services and equipment.

Vi. Interaction of the Players with

\section{INGRESS}

On this section, the relations defined between the elementary tetrad of the game and the Bartle profiles are exemplified according to the answers of Ingress players. In this analysis, the aspect of the tetrad technology is not discussed as exposed before.

\section{Achievers}

The "Achievers" profile appears on Ingress through the players who are head to play especially aiming at dominating portals and accumulating guns and score. On Pokémon Go this profile is more present because the Progress is the result of the catching of characters spread through the city. A player informed in an interview that because the cell phone's operating system is unlocked, he could catch characters of the game in several parts of the world without going out of his current geographical point, that means he caught characters in Brazil, North America, Europe, and Asia in a short period. That result in his banishment from Pokémon Go. Regarding aesthetics, the inventory screens and the possibilities of obtaining items are important for the achievers in Ingress, as is presented in figure 4 .
The locative structure in the games involves the following actors: the player's experience (intrinsic and extrinsic motivation), electronic devices (the hypermediacy state and the hybrid space) and the cities (heterotrophic and isotropic representation). The players are motivated by the competition and possibilities of entertainment caused by the game's narrative (Caillois 2001). Given the presented definitions, the locative structure configuration is exemplified on Board 2:

Figure 4: Inventory screen captured by the authors. The translation of the text: Ressonador = Resonator; Loja $=$ Store; Chaves do portal = Portal Keys; and Inventário = Inventory 
Through the mechanics' perspective, to obtain more items, such as guns and energy cubes, the player needs to access the "hack portal" button next to any portal. When it is the enemy team's portal the player risks being attacked, depending on the attack intensity, the player may be out of the game for a while and to revert this; it is necessary to catch more energy or to use more collected items for regeneration.

\section{Explorers}

The "Explorers" profile is the most common on Ingress and Pokémon Go as it was noticed after the interviews. Many players who were approached by this survey indicated the possibility of moving around the physical world as a motivation for these games. When

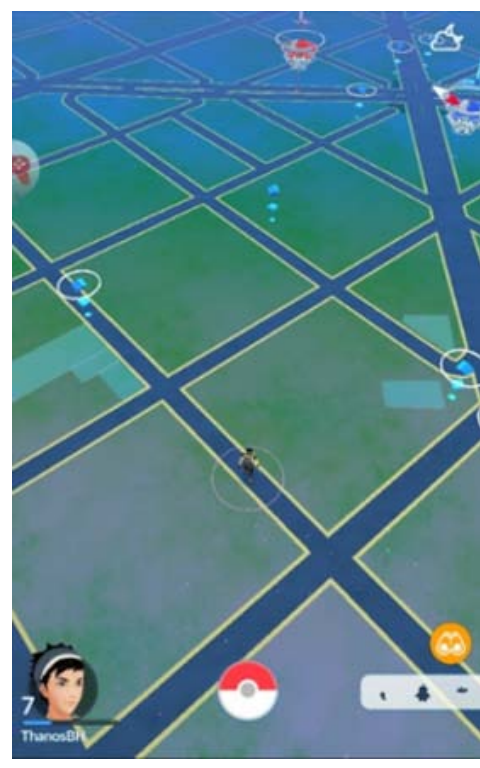

Figure 5: The first screen corresponds to the Pokémon Go map's aesthetic, while the second screen is from Ingress. The translation of the text: Portal under attack

The achievers and explorers profiles many times may be confused. The main mechanics of Ingress is related to locative interaction of the player to collect items, attack portals and create fields of influence. These fields of influence are the result of "links" between portals of the same team. Once a field of influence was established, the enemy team cannot create "links" of portals that are in this perimeter and "links" that go beyond the region of influence. On the interviews, one player said that in an event promoted by Niantic called Mission Day some Resistance team members were able to create fields of influence that covered entirely the state of Rio de Janeiro. The dislocation through the urban ambiance is also implied in the story because according to the game, emergency portals are spread around the city and each team has a purpose of usage.

The mechanics to brood the Pokémon eggs on Pokémon Go serves the explorer profile. According to the participant observation and the consult on researches on Pokémon Go, to be able to brood the eggs it is necessary to cover a $2 \mathrm{~km}, 5 \mathrm{~km}$ or $10 \mathrm{~km}$

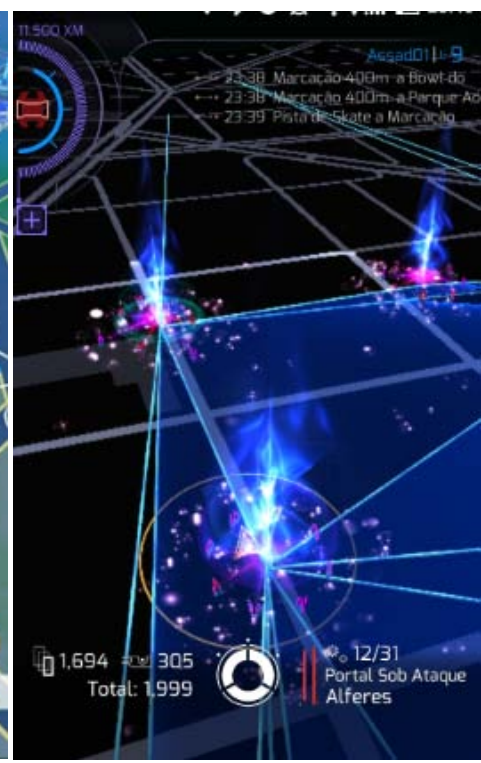

the players were asked about their motivation to play Ingress, Pokémon Go or other game of this style, most of the answers were related to the trajectory in the physical world. Some of the answers the players gave and that exemplify this motivation are the possibility of going out; not being stuck in a closed place; to be able to visit tourist and historical attractions; to get to know new places; and to explore the real world to play.

Through the aesthetic bias, it is obvious the necessity of moving because the main screen of both games is the city map stylized from Google Maps. Figure 5 presents the main screens of Ingress and Pokémon Go.

distance depending on the egg that was obtained. To brood this egg, the player must move in slow speed, that means it motivates him to walk. In some cases, some players use bicycles to speed up the process as it was noticed in the participant information.

Regarding the explorer profile, players state they use weather forecasting application because the city spatiality is not limited to urban constructions. The transcendence does not occur between the virtual and the physical but also inside the virtual ambiance when the player extrapolates the game's interface to access other application to complete his goals on Ingress.

\section{Socialzers}

On the first access to Ingress, right after the player selects the team, the application reports to the community a new member just got in through an intern system of message exchange in the game's interface. More experienced players advise the new players on the game mechanics and team strategies. The internal message exchange screen may be accessed from the main screen, and it is exemplified in Figure 6. 


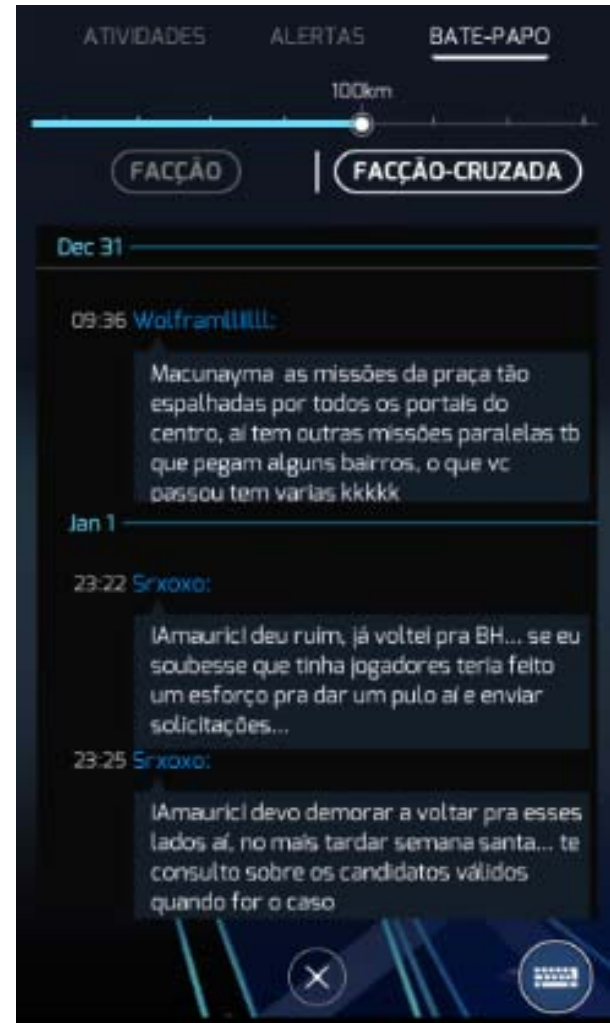

Figure 6: Instant message exchange screen inside Ingress interface. The translation of the text

"Macunayma the square missions are so spread through all portals of downtown, there are other parallel missions as well, and they are in a few neighborhoods, the one you passed through has several kkkkkk" "Amauricl something went bad, I came back to $\mathrm{BH}$... if I knew there were players I would have put some effort on going over there and send requirements..." "Amauricl I might linger to come back there, at the latest on Holy Week...l'll check with you on the valid candidates if it is the case".

The internal message exchange screen is split into three tabs All, Faction and Alerts, and they may be managed according to the geographical distance from the current location of the player. This distance varies between area: regional and global. On the tab "All" the total of messages and activities of both teams, such as control of portals, are shown. On the tab "Faction" only the team's messages are shown, while on "Alerts" the system informs who is attacking a portal dominated by his team and when it is happening. During the research, the team's collaboration to annul an important enemy portal was requested. In two days the referred portal was dominated by the team, following all the steps and strategies of the players.

Besides, through this internal message exchange system, the new players are invited to participate in groups through Telegram and Whats App to receive more information on the team's strategies.
There are several groups related to Ingress where the players exchange their experiences. Besides going beyond the virtual ambiance by using the city as scenery, the game extrapolates its interface because of the socializers.

Several events are organized to play Ingress in groups. One of these events is the IFSIngress First Saturday that happens on the first Saturday of every month, and it aims at helping new players to level up and socialize with the rest of the players. There is also an international event called Mission Day that consists of reuniting the players of a city and having them performing missions together.

Killers

The profile "Killers" was identified when the players are motivated to destroy enemy portals. Some players said that when they find an enemy portal, they always attack. In this profile, when the players are next to enemy portals they prefer to attack and collect items.

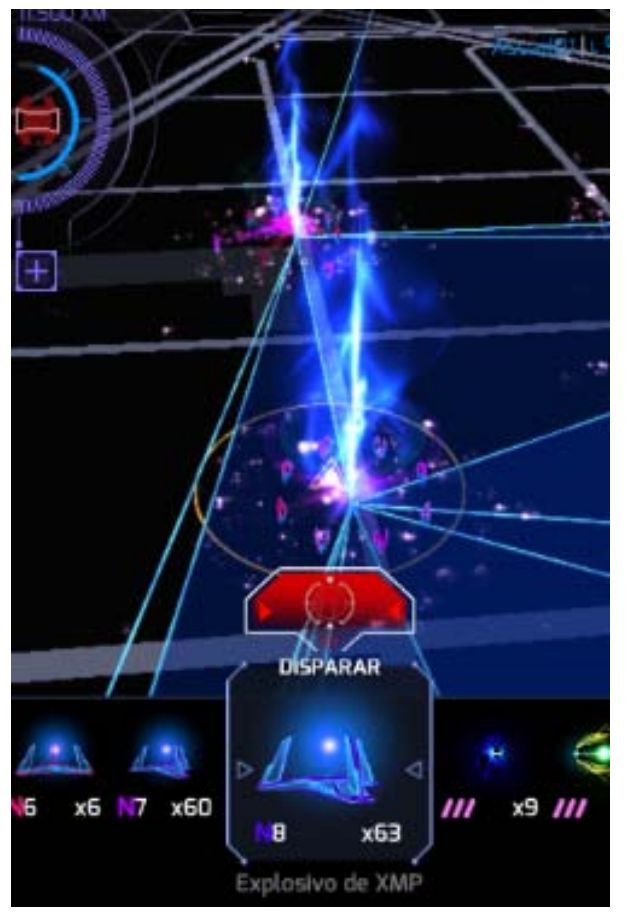

Figure 7: The screen presenting the items for an attack.

The translation of the text: Disparar $=$ Shoot

Through the aesthetic bias, it is possible to imply that the sound alert indicating enemy portals and the contrast between blue and green (to identify the portals) are important for the Killers profile. Regarding the mechanics, the attack to the enemy portals depends on its location, level and amount of items as it is exemplified in figure 7 . Ingress level is important regarding the quality of the item of that level, in case it is on level 2 it is only possible to use items in this level. The amount of items is limited so it is necessary to collect them in portals and a player may count with until 2000 items on his arsenal. 


\section{Players' participation}

This study identified coincidences between the spatiality of Ingress and Pokémon Go after comparing the interfaces in different situations. Figure 8 corresponds to a comparison of Pokémon Go and Ingress interfaces at the same place.
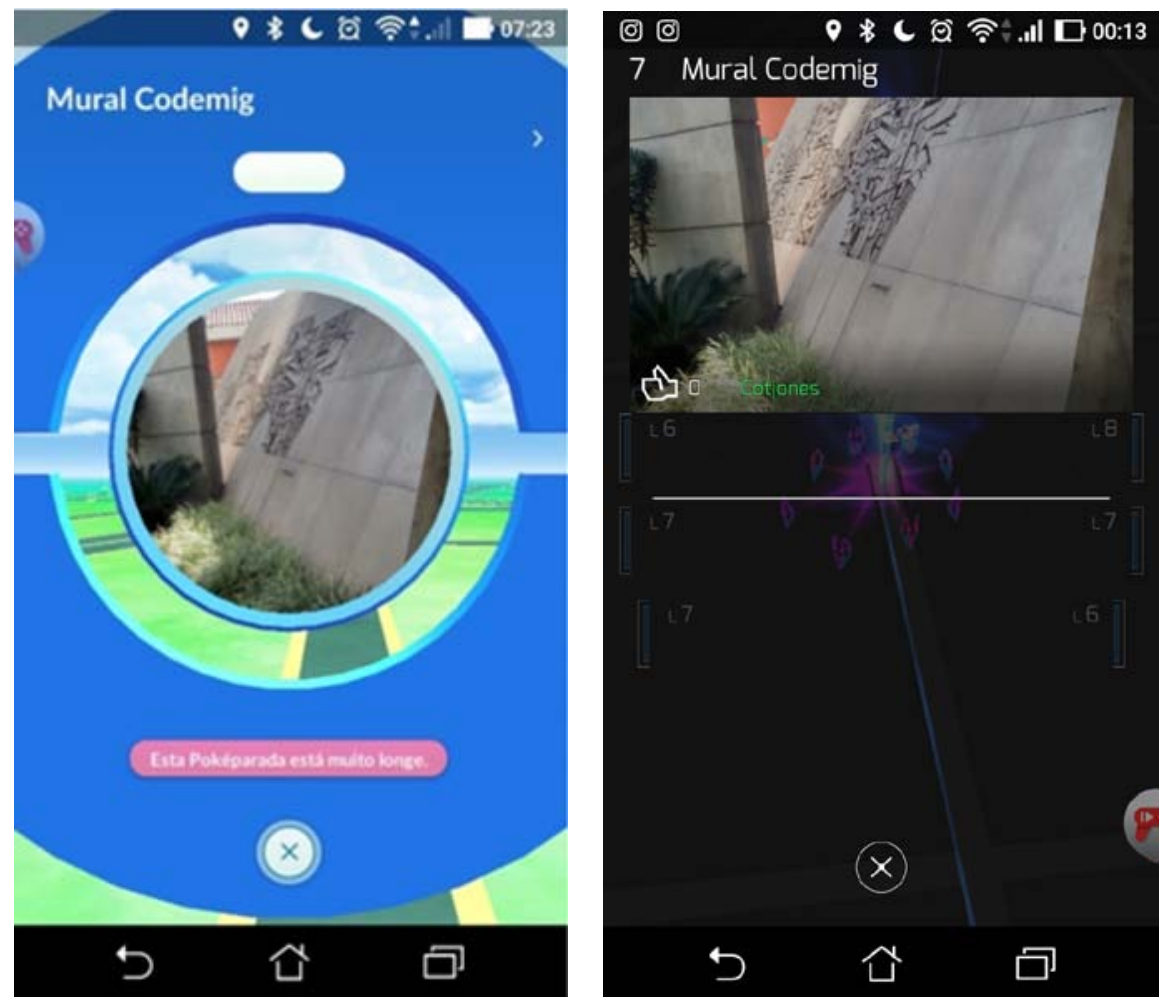

Figure 8: Comparison screen of Pokémon Go and Ingress interfaces

This similarity between the spatiality of Ingress and Pokémon Go were identified in other portals as it is on Figure 9, with both games interface. The first picture on figure 9 is the Pokémon Go screen while the other is Ingress screen.
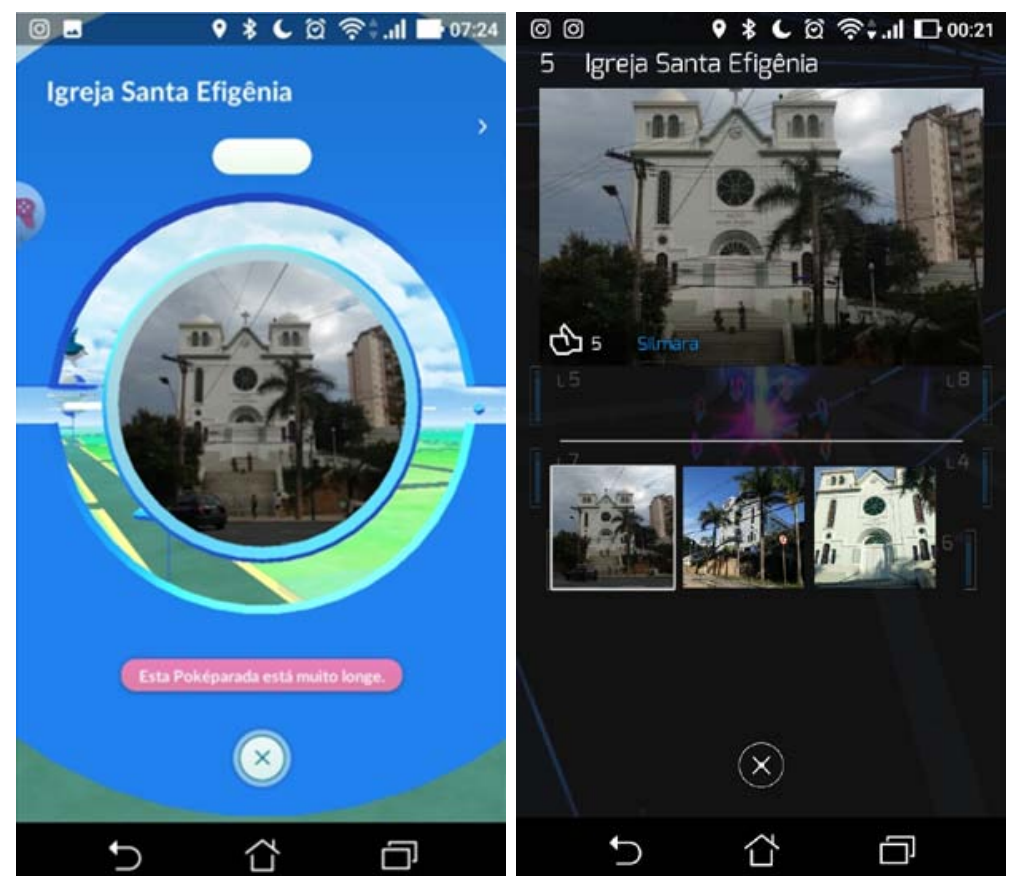

Figure 9: Comparison between Pokémon Go and Ingress screen from the same place 
Through an interview via Telegram with a player of advanced level, it was explained how the dynamics of portal addition works on Ingress. Any player higher than level 11 may submit areas to become portals. Players higher than level 12 evaluate this indication after they attend training about the evaluation of portals that is provided by Niantic. At last, who approves the indication submitted by the evaluators is the game's developer itself. Niantic creates spatiality on Pokémon Go from the areas approved by the players of Ingress. In addition to this analysis with the surveys' data, Ingress portals become Poke Stops and Gyms on Pokémon Go. Niantic uses the involvement of Ingress and Pokémon Go players to feed the spatial database of its games. In the surveys, some players said that a Pokémon Go player needs to go to Ingress to be able to create Poke Stops and Gyms. In some cases, some players leave Pokémon Go to play Ingress because of the mechanics.

\section{Vil. Conclusion}

The validation strategy of geographical areas in several cities around the world assumed by Niantic has been very successful. The company's spatiality production of locative games extrapolates its developer team and city, and it embraces the involvement and activity of the players. Through the competition between the groups and the hierarchy of players, the places of the real world are referenced and photographed at a low price. Niantic may use both extrinsic and intrinsic motivation. Through extrinsic motivation, the players feed the database of geo-referenced areas aiming at an improvement of Pokémon Go, and they do not care about playing Ingress to reach higher levels. While Ingress players use intrinsic motivation to expand the spatiality of their group. At this point, Ingress is not only a simple game but a strategy to feed the geographic database of Niantic and Google.

From this geographic database, Niantic may propose new locative games and test new mechanics. Through Ingress, the number of users that interact with portals and their time of interaction can be deduced. For the players, Ingress is a simple amusement that mixes physical space and the electronic narrative of the game. While for the developer, Ingress also works as a platform to feed and update its database of areas georeferenced around the world.

\section{ACKNOWLeDgment}

The authors are grateful to CNPq, FAPEMIG and CoPIC/FUMEC, Brazilian research funding agencies, for the financial support to this work.'

\section{References Références Referencias}

1. ATTFIELD, S., Kazai, G., Lalmas, M. and Piwowarski, B. (2011) Towards a science of user engagement. In: WSDM workshop on user modelling for Web applications. 2011. Available at $<$ http://ir.dcs.gla.ac.uk/ mounia/Papers/engagement .pdf $>$ Accessed in December 7 of 2018.

2. BARTLE, R. (1996). Hearts, Clubs, Diamonds, Spades: Players Who Suit Muds. In: Players Who Suit MUDs. MUSE Ltd, Colchester, Essex, United Kingdom, 1996. Available at $<$ https://mud.co.uk/ richard/hcds.htm\#1>. Accessed in: December 26 of 2018.

3. BOLTER, J. D.; GRUSIN, R. (2000). Remediation: understanding new media. Cambridge: The MIT Press.

4. CAILLOIS, R. (2001). Man, Play, and Games. Urbana, In: University of Illinois Press.

5. CRESSWELL, T. (2009) Place. Available at: <https: //booksite.elsevier.com/brochures/hugy/SampleCon tent/Place.pdf>. Elsevier Inc. Accessed in: December 23 of 2018.

6. CSIKSZENTMIHALYI, M. (2209) Flow: The Psychology of Optimal Experience. Harper Collins.

7. DOVEY, J.; KENNEDY, H. W. (2006). Game cultures: Computer games as new media. New York: Open University Press.

8. FRAGOSO, S. (2015). A experiência espacial dos games e outros medias: notas a partir de um modelo teórico analítico das representações do espaço. In: Comunicação e Sociedade, vol. 27, 2015, pp. 195 - 212 doi: http://dx.doi.org/10.17231/ comsoc. 27.

9. HATFIELD, T. (2018). Ingress: The game that reveals Google's secret war to control London. In: The Guardian. July 4 of 2014. Available at: < https://www.theguardian.com/technology/2014/jun/ 04/ingress-the-game-that-reveals-googles-secretwar-to-control-Iondon>acessadoem 14 de dezembro de 2018.

10. HILL, R.; HODSON, D. (2014). The art and science of live, virtual, and constructive simulation for test and analysis. Journal of Defense Modeling and Simulation: Applications, Methodology, Technology, v. 11, n. 2, p. 77-89, 2014. DOI: 0.1177/154851291 3506620.

11. HUIZINGA, J. (1968). Homo Ludens: A Study of the Play Element in Culture. Beacon Press.

12. INGRESS, Help (2018). Available at <https:// support.ingress.com/hc/pt-br/articles/207343987Crit\%C3\%A9rios-de-candidato-a-Portal >Acessado em 25 de novembro de 2018.

13. KIEFER,. and SCHEIDER, S. (2017). (Re-) Localization of Location-Based Games. In: ADVANCES in Geographic Information Science. Utrecht University Repository. Available at: <https:// dspace. library.uu.nl/handle/1874/342085>. Accessed in: 5 de dezembro de 2018.

14. MATLIN, M.W. (2009). Cognition. John Wiley \& Sons, Inc. 
15. MCGONIGAL, J. (2011). Reality Is Broken: Why Games Make Us Better and How They Can Change the World. Penguin Books.

16. MURRAY, J. H. (2003). Hamlet on the Holodeck The Future of Narrative in Cyberspace. MIT Press.

17. NIANTIC (2018). Available at https://www. nianticlabs.com/. Accessed in November 25 of 2018.

18. PREECE, J., ROGERS, Y., SHARP, H. (2013). Interaction Design: Beyond Human-Computer Interaction. John Wiley \& Sons, 2013.

19. SCHELL, J. (2008 The Art of Game Design: A Book of Lenses. Morgan Kaufmann, 2008.

20. WALTHER, B. K. (2005) Atomic actions-molecular experience: theory of pervasive gaming. Computers in Entertainment, v. 3, n. 2, July 2005. DOI: 10.1145/ 1077246.1077258.

21. WALZ, S. P. (2010) Toward a Ludic Architecture: The Space of Play and Games. Pittsburgh: ETC Press. 